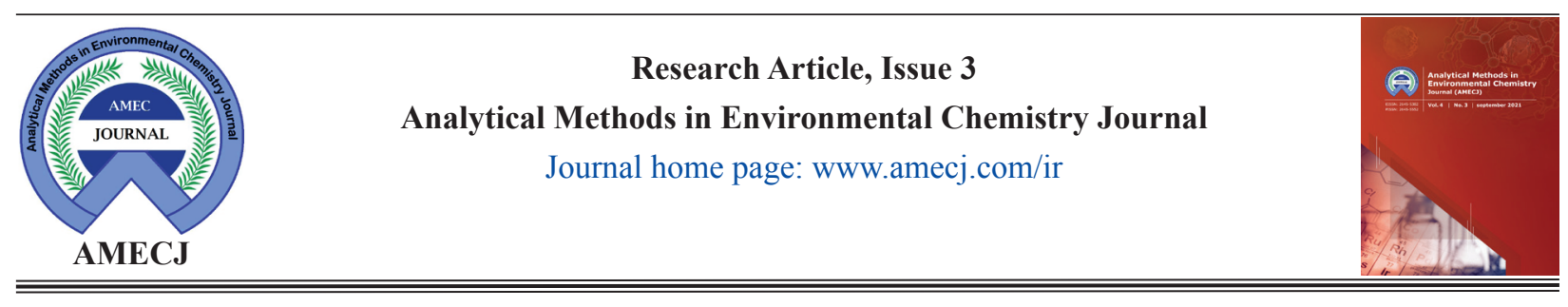

\title{
Developing a magnetic nanocomposite adsorbent based on carbon quantum dots prepared from Pomegranate peel for the removal of $\mathrm{Pb}(\mathrm{II})$ and $\mathrm{Cd}(\mathrm{II})$ ions from aqueous solution
}

\author{
Hamideh Asadollahzadeh ${ }^{\mathrm{a}, *}$, Mahdiyeh Ghazizadeh ${ }^{\mathrm{a}}$ and Mohammad Manzari ${ }^{\mathrm{a}}$ \\ ${ }^{a}$ Department of Chemistry, Faculty of Science, Kerman branch, \\ Islamic Azad University, Kerman, Iran, P. O. Box 7635131167, Kerman, Iran
}

\section{A R T I C L E I N F O :}

Received 2 Jun 2021

Revised form 5 Aug 2021

Accepted 27 Aug 2021

Available online 29 Sep 2021

Keywords:

Carbon quantum dots,

Iron oxide nanoparticles,

Adsorption,

Lead and Cadmium,

Isotherms,

Flame atomic absorption spectrometry

\begin{abstract}
A B S T R A C T
Agriculture waste is a good choice for the production of carbon dots owing to its abundance, wide availability, eco-friendly nature. In this study a novel magnetic bioadsorbent based on carbon quantum dots $\left(\mathrm{Fe}_{3} \mathrm{O}_{4}\right.$-PPCQDs) from Pomegranate peel (PP) was used as adsorbent to remove lead $(\mathrm{Pb})$ and cadmium $(\mathrm{Cd})$ from $50 \mathrm{~mL}$ of water and wastewater samples by magnetic solid phase extraction (MSPE). After adsorption ions with $\mathrm{Fe}_{3} \mathrm{O}_{4}$-PPCQDs at $\mathrm{pH}=6$, the concentration of $\mathrm{Pb}$ (II) and $\mathrm{Cd}$ (II) ions were determined by flame atomic absorption spectrometry (F-AAS). The manufactured of $\mathrm{Fe}_{3} \mathrm{O}_{4}$-PPCQDs and GO nanostructures were structurally characterized by scanning electron microscopy (SEM), transmission electron microscopy (TEM), X-ray diffraction (XRD) and Fourier transform infrared spectroscopy (FT-IR). The quantum dots were optically characterized by UV-Vis spectroscopy. Batch adsorption experiment was conducted to examine the effects of $\mathrm{pH}$, contact time, temperature and initial concentration of $\mathrm{Pb}(\mathrm{II})$ and $\mathrm{Cd}(\mathrm{II})$ from the water. The preconcentration factor and LOD for $\mathrm{Cd}$ and $\mathrm{Pb}$ were obtained 50 and $\left(1.3 \mu \mathrm{g} \mathrm{L}^{-1} ; 15.5 \mu \mathrm{g} \mathrm{L}-1\right)$, respectively. The equilibrium data of ions sorption were well described by Langmuir and Freundlich model. The $\mathrm{R}^{2}$ values obtained by Langmuir model were higher. The absorption capacity of $\mathrm{Fe}_{3} \mathrm{O}_{4}$-PPCQDs for cadmium and lead were obtained 17.92 and $23.75 \mathrm{mg} \mathrm{g}^{-1}$, respectively.
\end{abstract}

\section{Introduction}

Environmental pollution based on the organic chemical compounds (VOCs) and heavy metals (M) have needed a serious threat due to the rapid development of the chemical industry and the toxic effect in environment. The contamination of heavy metals in water through the industrial wastewater is the global environmental problems [1]. The heavy metals compounds cannot be decomposed naturally

\footnotetext{
*Corresponding Author: Hamideh Asadollahzadeh Email: asadollahzadeh90@yahoo.com https://doi.org/10.24200/amecj.v4.i03.149
}

and cause the various health problems in the living organism and human. Recently, the elimination of heavy metals is becoming a significant concern as a result of their persistence into the atmosphere [2]. Among of heavy metals, cadmium and lead $(\mathrm{Cd}$ and $\mathrm{Pb})$ can be discharged from the several industrial effluents. Cadmium is liberated into the environment from the steel production, the cement manufacture, the Ni-Cd battery manufacture, cadmium electroplating, the phosphate fertilizers etc. [3]. Bivalent cadmium causes a number of deformities and diseases in humans, such as the muscle cramps, the lung problems, the 
kidney degradation, the proteinuria, the skeletal deformation [4]. On the other hand, common anthropogenic causes of lead contamination in groundwater include the smelting, the mining, the consumption of fossil fuels and the incinerating solid waste [5]. Lead can cause a cognitive dysfunction in children, high blood pressure, the illnesses of the immune system and the reproductive system [6]. Numerous techniques have been used to reduce the harmful effects of cadmium and lead on water source, including the chemical oxidation and the reduction, the chemical precipitation, the ion exchange, the electrochemical processes, and the membrane filtration [7]. The performance and perform of above processes are difficult without any selectivity. However, among these methods, the adsorption technique is flexible, low cost and has a high efficient recovery [8]. Adsorption is a mass transfer process where a substance is transferred from the liquid phase to the surface of the solid through physical or chemical interaction. Many kinds of adsorbents, including the activated carbon [9], the inorganic minerals [10], the biomass adsorbents [11-13], and polymer [14-17] are used to remove the metal ions from the liquid phased such as water and wastewater. By-products from agriculture feed have always considered due to its availability and the cost features. Moreover, the other important characteristics are biocompatibility, biodegradability and the renewable [18]. Thus there is an interest in use of agricultural wastes as a source for preparation of carbon based nanomaterial. Carbon based quantum dots are new class of carbon nanomaterials that have been explored due to their excellent properties [19].

However, the separation of adsorbents, obtained from agricultural waste, required a high-speed centrifugation or filter due to they are too small [20]. Iron oxide has excellent magnetic properties, the high biocompatibility, easy separation through external magnetic field, reusability and comparatively low cost. The magnetic iron oxide was fixed inside the polymer adsorbent matrix with the highest adsorption rates [21]. The surface modification of the activated carbon-based iron oxide using the coating technique improves their sorption capacity because, the surface coating phenomenon helps to converting the closely packed cubic geometry of magnetic nanoparticles into compact [22].

Pomegranate peel (PP), as a by-product of the pomegranate juice industry is an inexpensive material. It is composed of several constituents, including polyphenols, ellagic tannin and ellagic acids [23]. So far, no study has been done on surface modification of iron oxide by using carbon quantum dots prepared from pomegranate peel for developing magnetic nanocomposite $\left(\mathrm{Fe}_{3} \mathrm{O}_{4}\right.$-PPCQDs). The PPCQDs adsorbent has generated from the pomegranate peel and functionalized with $\mathrm{Fe}_{3} \mathrm{O}_{4}$ as magnetic nanostructure which was used for removing toxic ions from wastewater. Another advantage is that the loaded adsorbents could be easily separated from the aqueous solution using magnet instead of centrifugation thus conserving energy. In this study, the material preparation, the characterization and the batch-type removal experiments were carried out wherein the feasibility of the above described composite for the removal of heavy metals $\mathrm{Cd}(\mathrm{II})$ and $\mathrm{Pb}(\mathrm{II})$ from aqueous solution which were investigated by varying the process conditions.

\section{Material and Methods}

\subsection{Apparatus}

The concentration of heavy metals $(\mathrm{Pb}$ and $\mathrm{Cd})$ in the aqueous solution was measured using flame atomic absorption spectrometry (F-AAS, Model AAnalyst 800, Air acetylene, Perkin Elmer, USA). The wavelength of $217.0 \mathrm{~nm}$ (Slit :1, Current lamp: $5 \mathrm{~mA}$ ) and $228.8 \mathrm{~nm}$ (Slit: 0.5, Current lamp: $3 \mathrm{~mA}$ ) was used for lead and cadmium determination, respectively. The working ranges for lead and cadmium were achieved 2.5-20 $\mathrm{mg} \mathrm{L}^{-1}$ and $0.2-1.8$ $\mathrm{mg} \mathrm{L}^{-1}$, respectively by sensitivity of $0.06 \mathrm{mg} \mathrm{L}^{-1}$. The LOD of F-AAS for lead and cadmium was achieved $0.1 \mathrm{mg} \mathrm{L}^{-1}$ and $0.05 \mathrm{mg} \mathrm{L}^{-1}$, respectively. The auto-sampler from 0.5 to $5 \mathrm{~mL}$ was used for sample introduction to F-AAS. The $\mathrm{pH}$ was measured by electronic $\mathrm{pH}$ meter (Benchtop meter inoLab pH 7110 model, WTW company, Germany). 


\subsection{Chemicals}

Pomegranate peel were obtained from Mahan, Kerman, Iran. Sodium hydroxide $(\mathrm{NaOH})$, cadmium nitrate tetrahydrate $\left(\mathrm{Cd}\left(\mathrm{NO}_{3}\right)_{2} \cdot 4 \mathrm{H}_{2} \mathrm{O}\right)$, lead nitrate $\left(\mathrm{Pb}\left(\mathrm{NO}_{3}\right)_{2}\right)$, the ferric chloride hexahydrate $\left(\mathrm{FeCl}_{3} \cdot 6 \mathrm{H}_{2} \mathrm{O}\right)$, the ferric sulfate heptahydrate $\left(\mathrm{FeSO}_{4} \cdot 7 \mathrm{H}_{2} \mathrm{O}\right)$ hydrochloric acid $(\mathrm{HCl})$ with a purity of $37 \%$, nitric acid $\left(\mathrm{HNO}_{3}\right)$ with purity $63 \%$ was purchased from Merck and all the chemical reagents were analytical grade. All the aqueous solutions were prepared by using double distilled water. The $\mathrm{pH}$ of the solution was adjusted and measured using electronic $\mathrm{pH}$ meter. The $\mathrm{pH}$ of the solution was adjusted by adding $0.1 \mathrm{M} \mathrm{HCl}$ or $0.1 \mathrm{M} \mathrm{NaOH}$ and measured using electronic $\mathrm{pH}$ meter (Benchtop meter inoLab pH 7110 model, WTW company, Germany).

\subsection{Synthesis of Magnetic Carbon Quantum Dots $\left(\mathrm{Fe}_{3} \mathrm{O}_{4}\right.$-CQDs)}

The pomegranate peel (PP) has carbon structure which was ground after washed/ dried in the oven $100^{\circ} \mathrm{C}$. The ground powder is sifted by small mesh to obtained for used for synthesis of CQDs. First of all, 100 grams of ground powder of the pomegranate peel (PP) mixed with 8 Liters of DW in the 500 $\mathrm{mL}$ closed container. The closed container adjusted on temperature between $200-230^{\circ} \mathrm{C}$ for two days and then the temperature decreased (cooling) up to room temperature for one day. The sediments were separated in by Watman filter paper based on the vacuum pump and the black brown product is created. After UV irradiation $(400 \mathrm{~nm})$, the color of product change into blue photoluminescence which was showed that a quantum dot particles synthesized correctly. The CQDs cab be absorbed the UV irradiation at $220 \mathrm{~nm}$ spectrophotometer. The final liquid product filtered / dried completely at temperature of $100{ }^{\circ} \mathrm{C}$ and finally converted into powder. The powder put in the oven based on quartz type, $\mathrm{N}_{2}$ gas and $700{ }^{\circ} \mathrm{C}$ (1 hour). Then the product powder was carbonized and impurities get out of oven. After synthesis PPCQDs, the absorption of UV was obtained at $210 \mathrm{~nm}$ which was confirmed by UV peak by spectrophotometer (Fig.1a). the magnetic $\mathrm{Fe}_{3} \mathrm{O}_{4}$-PPCQDs were prepared by coprecipitation of $\mathrm{FeCl}_{2} \cdot 4 \mathrm{H}_{2} \mathrm{O}$ and $\mathrm{FeCl}_{3} \cdot 6 \mathrm{H}_{2} \mathrm{O}$, in the presence of PPCQDs [24]. To prepare the nano magnetic PPCQDs, $10 \mathrm{mg}$ of PPCQDs in $10 \mathrm{~mL}$ of DW was ultra-sonicated for I $\mathrm{h}$. To the resulting mixture was added $12.5 \mathrm{~mL}$ solution of $\mathrm{FeCl}_{2} \cdot 4 \mathrm{H}_{2} \mathrm{O}(125 \mathrm{mg})$ and $\mathrm{FeCl}_{3} \cdot 6 \mathrm{H}_{2} \mathrm{O}(200 \mathrm{mg})$ in deionized water $(10 \mathrm{~mL})$ at room temperature. Then, 30\% ammonia solution was added for the $\mathrm{pH}$ $=11$ and the temperature was increased to $60{ }^{\circ} \mathrm{C}$. After being stirred for $1 \mathrm{~h}$, the product was cooled at $25^{\circ} \mathrm{C}$. finally, the black powder of $\mathrm{Fe}_{3} \mathrm{O}_{4}$-PPCQDs centrifuged at $4000 \mathrm{rpm}$ for $20 \mathrm{~min}$, washed and dried at $75^{\circ} \mathrm{C}$ (Fig. 1 b).
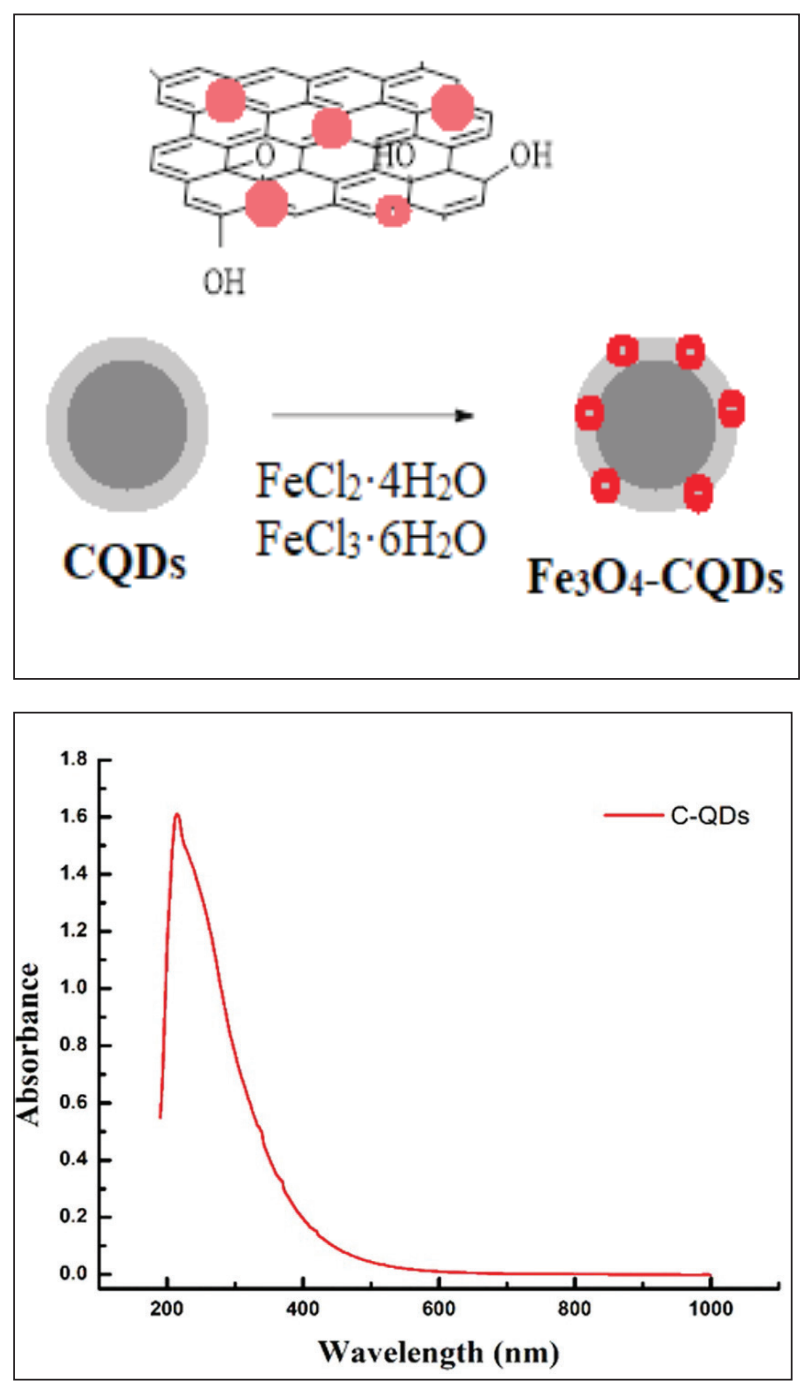

Fig.1. a) UV absorption by CQDs product b) The mechanism of synthesis of $\mathrm{Fe}_{3} \mathrm{O}_{4}$-PPCQDs 


\subsection{Batch mode adsorption and analytical procedure}

Adsorption of $\mathrm{Pb}(\mathrm{II})$ and $\mathrm{Cd}(\mathrm{II})$ based on $\mathrm{Fe}_{3} \mathrm{O}_{4}^{-}$ PPCQDs adsorbent was achieved in optimized experimental conditions such as $\mathrm{pH}$, the contact time, the amount of adsorbent and temperature. The experiments were carried out in $50 \mathrm{ml}$ Erlenmeyer flasks. Experiment parameters were achieved from $\mathrm{pH} 2$ to 8 , the sample volume of $50 \mathrm{~mL}$, the contact time between 2 - 60 minute, the amount of biosorbent from 0.01 to $0.2 \mathrm{~g}$, the temperature between $5-45^{\circ} \mathrm{C}$ and the concentration of ions 5-150 $\mathrm{mg} \mathrm{L}^{-1}$. To adjust required The $\mathrm{pH}$ of aqueous solution was adjusted with $\mathrm{HCl}(0.1 \mathrm{M})$ and $\mathrm{NaOH}$ $(0.1 \mathrm{M})$. Finally, the thermodynamic parameters and isotherms were studied. The $\mathrm{Fe}_{3} \mathrm{O}_{4}$-PPCQDs were separated with a magnet using its magnetic field, and the filtrate was kept for the further determination of remaining $\mathrm{Pb}(\mathrm{II})$ and $\mathrm{Cd}(\mathrm{II})$ in water by F-AAS after back extraction solid phase by $1 \mathrm{~mL}$ mixture of $\mathrm{HNO}_{3} 0.1 \mathrm{M} / \mathrm{DW}$. Moreover, the linear ranges of MSPE procedure for cadmium and lead based on $\mathrm{Fe}_{3} \mathrm{O}_{4}$-PPCQDs were achieved 4-20 $\mu \mathrm{g} \mathrm{L}^{-1}$ and $50-140 \mu \mathrm{g} \mathrm{L}^{-1}$, respectively ( $\mathrm{RSD}_{0}<2.4$ ). So, the trace analysis of lead and cadmium (sub-ppb) can be created by the $\mathrm{Fe}_{3} \mathrm{O}_{4}$-PPCQDs adsorbent. The quantity of adsorbed ion per unit mass of biosorbent was calculated from Equation 1:

$$
\mathrm{q}_{\mathrm{e}}=\left(\mathrm{C}_{0}-\mathrm{C}_{\mathrm{e}}\right) \times V / \mathrm{m}
$$

where $\mathrm{C}_{\mathrm{o}}$ and $\mathrm{C}_{\mathrm{e}}$ are the concentrations of $\mathrm{Pb}(\mathrm{II})$ and $\mathrm{Cd}(\mathrm{II})$ at the beginning and at the end of the adsorption process.

\section{Result and discussion}

\subsection{Characterization}

$\mathrm{X}$-ray diffraction (XRD) patterns were recorded on a Seifert TT 3000 diffractometer (Ahrensburg, Germany). The specific surface areas and pore volume of the sorbents were calculated by the BrunauerEmmett-Teller (BET) and Barrett-Joyner-Halenda (BJH) methods, respectively. Scanning electron microscopy (SEM, Phillips, Netherland) was used for surface image of the CQDs The morphology of sorbent was examined by transmission electron microscopy (TEM, Philips, Netherland). The Fourier transform infrared spectrophotometer (FTIR, Bruker $\mathrm{GmbH}$, Germany) using $\mathrm{KBr}$ pelleting method was used in the $4000-200 \mathrm{~cm}^{-1}$

\subsection{Fourier-transform infrared spectroscopy (FTIR)} The FTIR spectra of $\mathrm{Fe}_{3} \mathrm{O}_{4}$-PPCQDs adsorbent are shown in Figure 2. The prime spectrum of FTIR of CQDs is shown in black line as nonactivated form (Fig. 2a) and red line (activated/ $\mathrm{HNO}_{3}$ ) which has different wavenumbers but both of them is similar. In these figures, the peak of $1020 \mathrm{~cm}^{-}$ ${ }^{1}, 1200 \mathrm{~cm}^{-1}, 1250 \mathrm{~cm}^{-1}$ belong to $\mathrm{C}-\mathrm{O}$ bond and the peak of $1381 \mathrm{~cm}^{-1}$ shows the formation of $\mathrm{C}-\mathrm{H}$ bond. Additionally a peak of $1585 \mathrm{~cm}^{-1}$ is observed for $\mathbf{C}=\mathbf{C}$ bond and the another peak appeared in

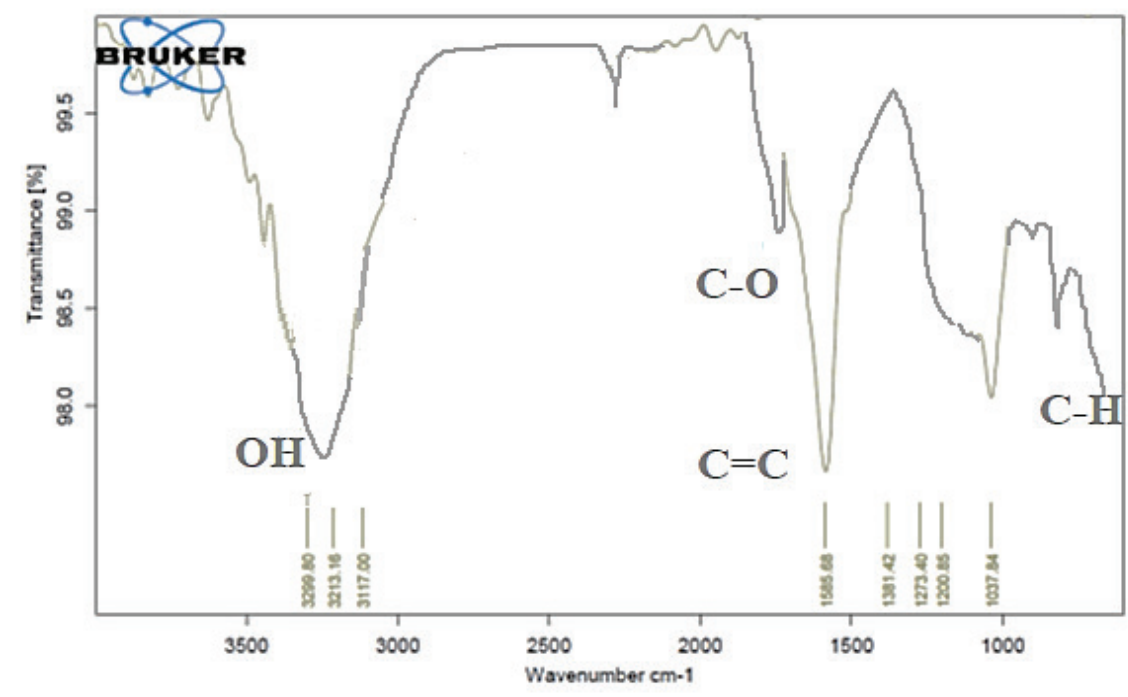

Fig.2(a). The spectrum of FTIR of CQDs 


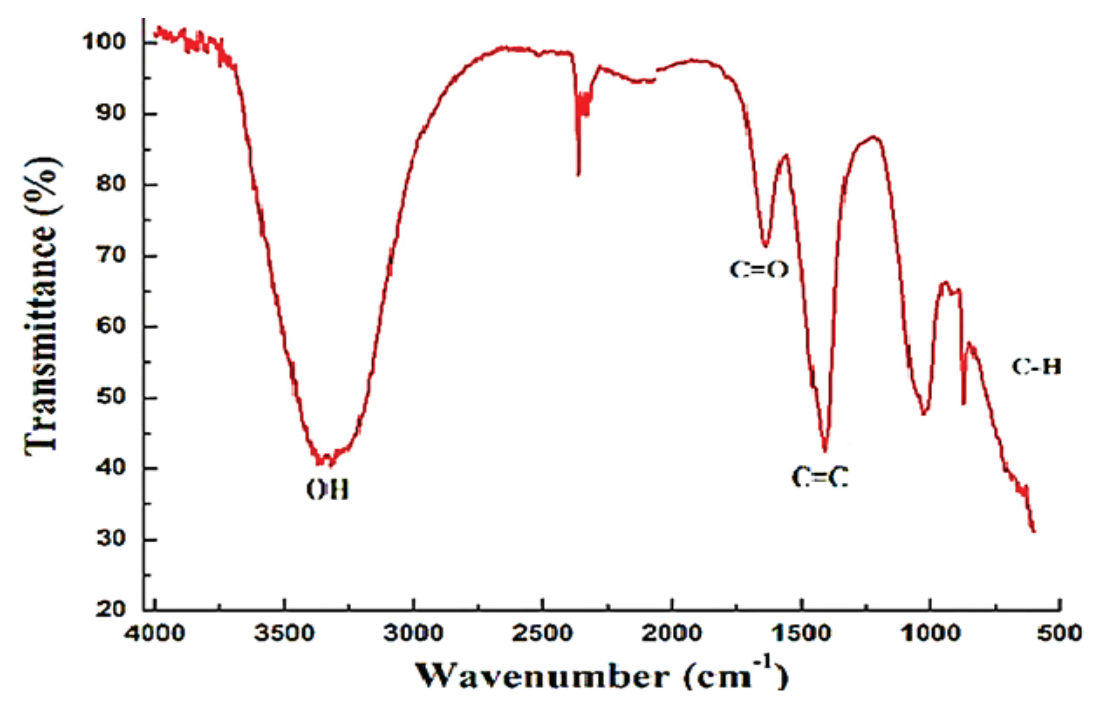

Fig.2(b). The spectrum of FTIR of $\mathrm{HNO}_{3}$-CQDs

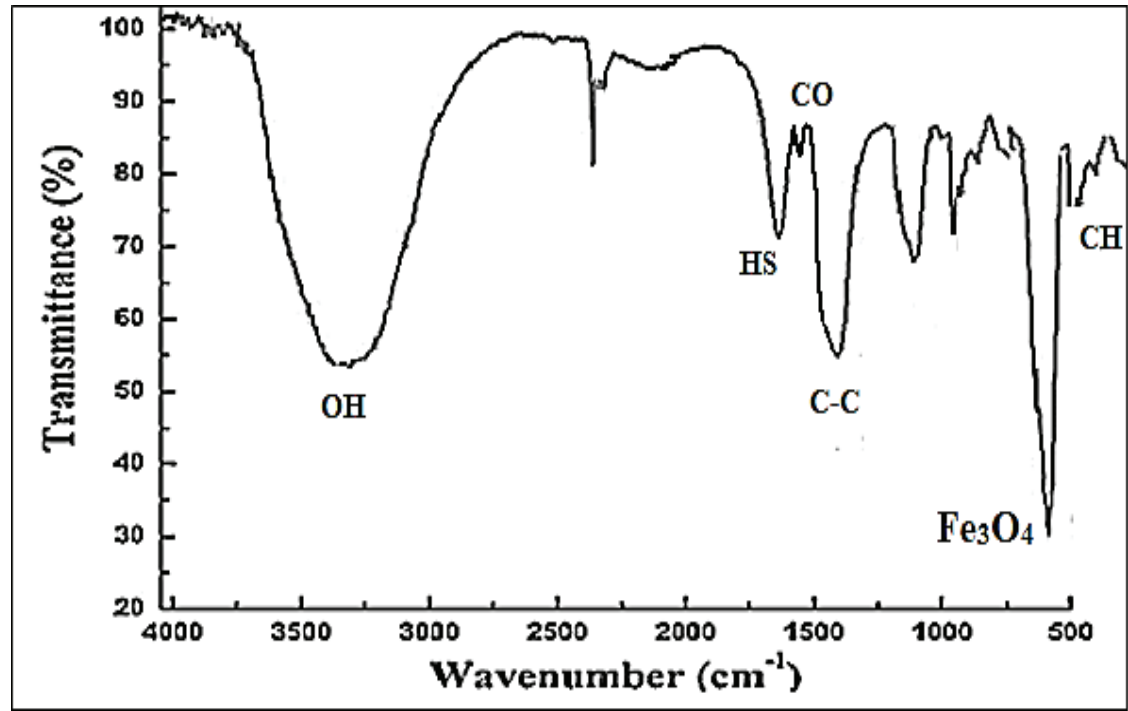

Fig.2(c). The spectrum of FTIR of $\mathrm{Fe}_{3} \mathrm{O}_{4}$-PPCQDs

$3300 \mathrm{~cm}^{-1}$ shows the $\mathrm{O}-\mathrm{H}$ bond. In Figure 2 (b), the red graph is the sample activated with nitric acid vapour. Meanwhile similar peaks of 3340 $\mathrm{cm}^{-1}$ (O-H bond) were observed in Figure 2(a,b). In addiition FTIR of $\mathrm{Fe}_{3} \mathrm{O}_{4}$-PPCQDs was shown in Figure $2 \mathrm{C}$ which has a peak in $582 \mathrm{~cm}^{-1}$ belong to $\mathrm{Fe}_{3} \mathrm{O}_{4}$.

\subsection{XRD spectra of CQD}

In Figure 3, the X-ray diagram was shown for carbon quantum dots(CQDs) and magnetic carbon quantum dots $\left(\mathrm{Fe}_{3} \mathrm{O}_{4}\right.$-PPCQDs). The XRD curve of $\mathrm{Fe}_{3} \mathrm{O}_{4}$-PPCQDs is similar to simple form of CQDs. In this pattern two main Peaks in $2 \theta$ is equal to $22-24$ degrees and 45 degrees were observed. The observed wide peak is in the intensity of 24 degrees in page (002) relates to the graphite. The width peak can have related to mall size of carbon quantum dots. The observed $\mathrm{Fe}_{3} \mathrm{O}_{4}$-PPCQDs peak in 45 degree angle relate to (101) which indicates similar to graphene formed by quantum dot particles. The XRD pattern for CQDs is similar to $\mathrm{Fe}_{3} \mathrm{O}_{4}$-PPCQDs which was indicated that carbon quantum dots modified with $\mathrm{PP}$ and $\mathrm{Fe}_{3} \mathrm{O}_{4}$ did not changed on the structural order of CQDs. 


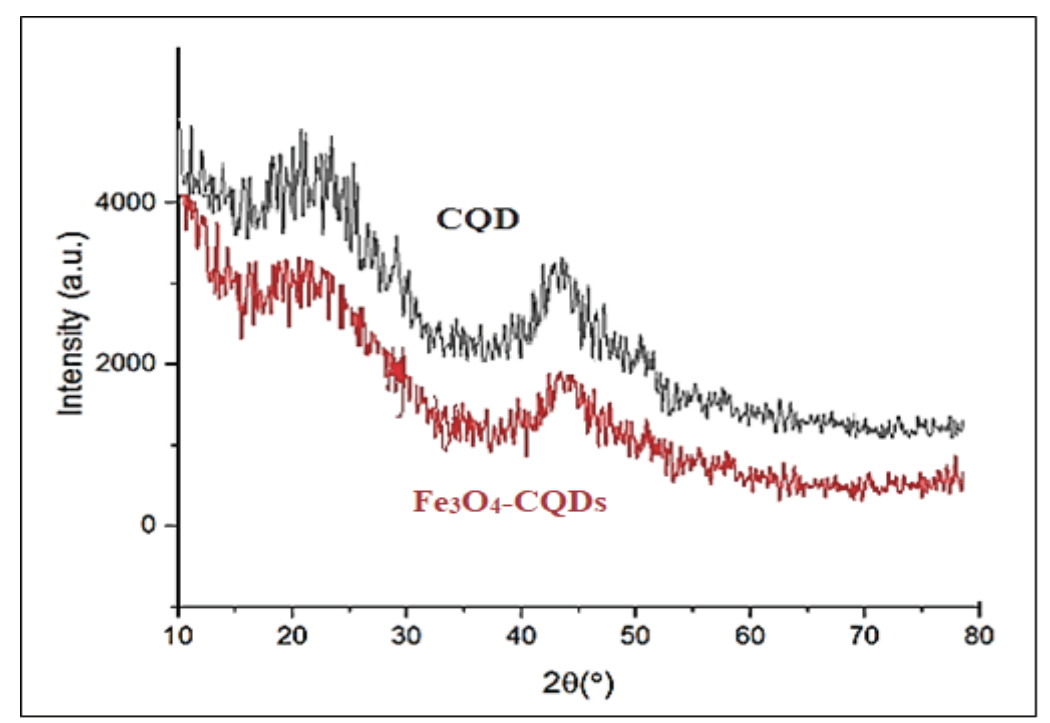

Fig.3. The XRD diagram of CQDs and $\mathrm{Fe}_{3} \mathrm{O}_{4}-\mathrm{PPCQDs}$

\subsection{Field emission scanning electron microscope (FE-SEM)}

The surface morphology of the CQDs was reported a field emission scanning electron microscope (FESEM). The FE-SEM of CQDs have been shown in Figure 4(a). The CQDs primary samples were formed as blocks of nano particles carbon. The blocks are as a colony and forms big volume of CQDs. The smallest size the structure was between 10 to 30 nanometer which consists of very small particles of CQDs. The FE-SEM of the $\mathrm{Fe}_{3} \mathrm{O}_{4}^{-}$ PPCQDs was shown in Figure 4(b) with size of 10$25 \mathrm{~nm}$.

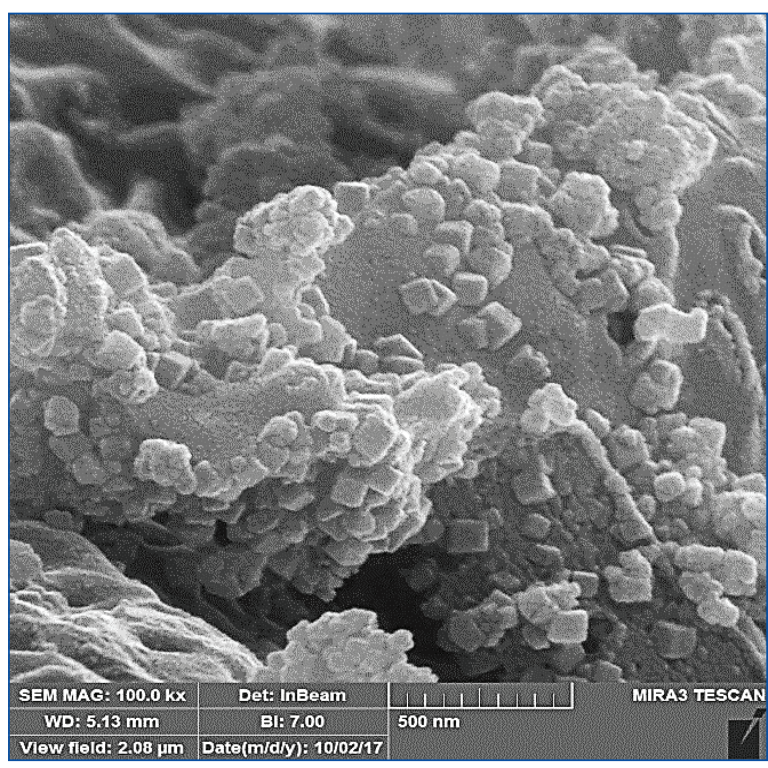

Fig.4a. The FESEM of CQDs

\subsection{Transmission electron microscopy (TEM)}

Transmission electron microscopy (TEM) was used to study of the nanostructure size. The microscopic pictures of the CQDs have been shown in Figure 5a. These pictures are shown clearly a magnified picture which the carbon particles are so small. Moreover, the formation of $\mathrm{Fe}_{3} \mathrm{O}_{4}$-PPCQDs has very small particles which is clearly visible by TEM (Fig.5b).

\subsection{Bach adsorption studies \\ 3.6.1. pH dependent studies}

The effect of $\mathrm{pH}$ (Fig. 6a and b) on the adsorption of $\mathrm{Pb}$ (II) and $\mathrm{Cd}$ (II) ions was studied by $\mathrm{Fe}_{3} \mathrm{O}_{4}$-PPCQDs.

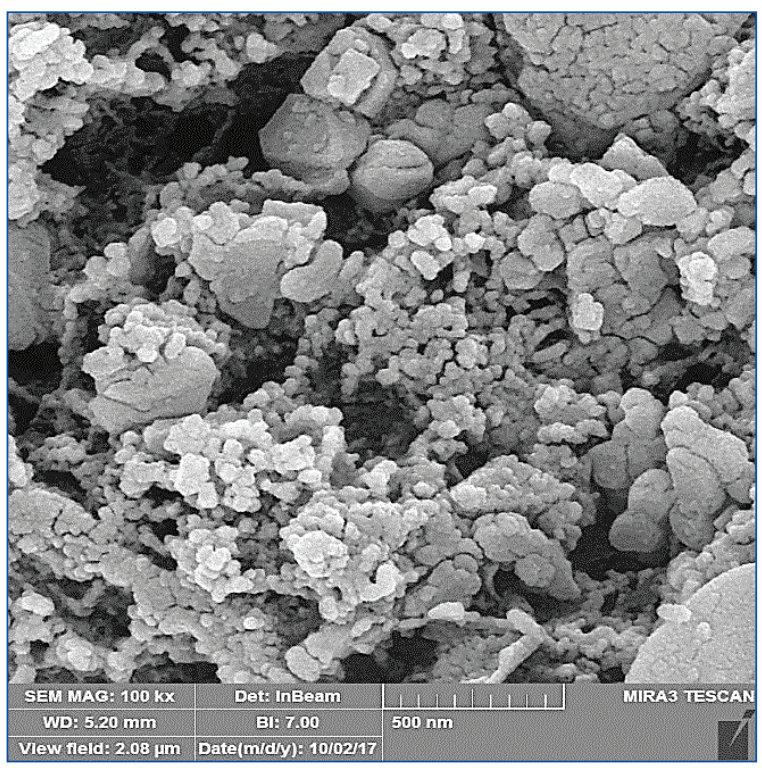

Fig.4b. The FESEM of $\mathrm{Fe}_{3} \mathrm{O}_{4}$-CQDs 


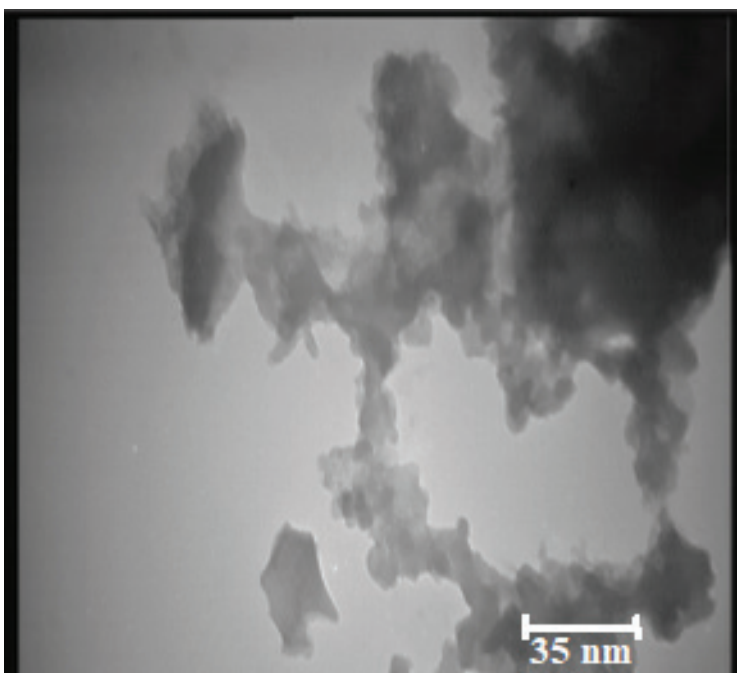

Fig.5a. The TEM of CQDs

In order to determine the optimum $\mathrm{pH}$, the $\mathrm{pH}$ range between 2.0-11.0 was evaluated for $\mathrm{Pb}$ (II) and $\mathrm{Cd}$ (II) ions. While screening the $\mathrm{pH}$ values, all the other process variables were kept constant. A control experiment was also run (in the absence of $\mathrm{Fe}_{3} \mathrm{O}_{4}$ PPCQDs) for the removal $\mathrm{Pb}(\mathrm{II})$ and $\mathrm{Cd}(\mathrm{II})$ to explore the effect of chemical precipitation (Fig. 6a). The control experiment revealed that there was no removal of $\mathrm{Pb}$ (II) and $\mathrm{Cd}(\mathrm{II})$ up to $\mathrm{pH} 7.0$ but when the $\mathrm{pH}$ was more than 7.0 both ions precipitated as hydroxides $\left[\mathrm{Pb}(\mathrm{OH})_{2}\right.$ and $\left.\mathrm{Cd}(\mathrm{OH})_{2}\right]$ in the solution thus, leading to their complete removal without $\mathrm{Fe}_{3} \mathrm{O}_{4}$-PPCQDs. Also, the adsorption of $\mathrm{Fe}_{3} \mathrm{O}_{4}$-PPCQDs was shown in Figure 6b. Due to interaction of ions with adsorbent, the maximum removal for $\mathrm{Pb}(\mathrm{II})$ and $\mathrm{Cd}(\mathrm{II})$ was achieved at

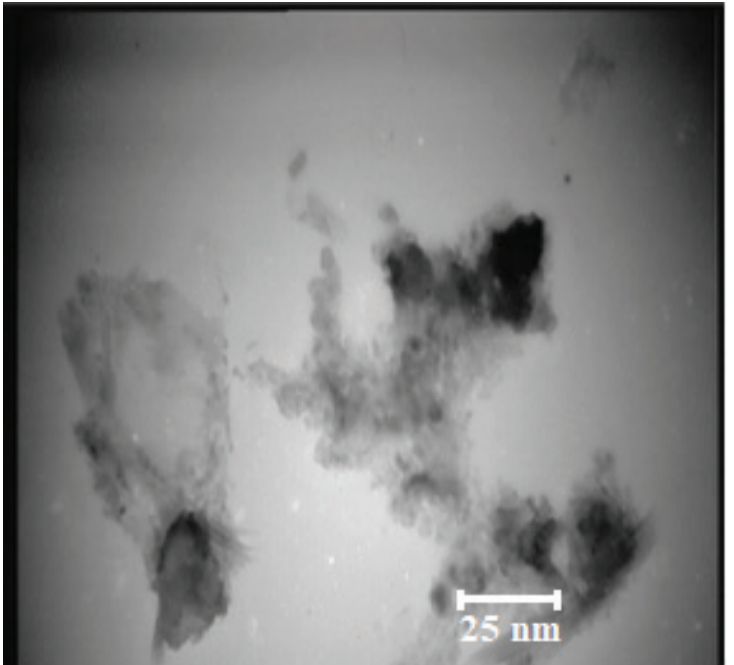

Fig.5b. The TEM of $\mathrm{Fe}_{3} \mathrm{O}_{4}$-PPCQDs

$\mathrm{pH}$ 6.0. The adsorption of $\mathrm{Pb}$ (II) and $\mathrm{Cd}(\mathrm{II})$ was decreased at lower and upper $\mathrm{pH}$ of $6(5.5>\mathrm{pH}>6.5)$. This behavior may be due to the reason that: lower $\mathrm{pH}$ leads to an abundance of hydronium ions $\left(\mathrm{H}_{3} \mathrm{O}^{+}\right)$ in the solution that causes competition between hydronium ions and $\mathrm{Pb}(\mathrm{II})$ and $\mathrm{Cd}(\mathrm{II})$ ions for adsorption onto $\mathrm{Fe}_{3} \mathrm{O}_{4}$-PPCQDs. Thereby lowering the overall adsorption efficiency of these metal ions occurred at lower $\mathrm{pH}$ [25]. On the other hand, by increasing $\mathrm{pH}$, the adsorption also increased, which can be showed that in this range (neutral and weakly acidic) most metals are available as soluble and free cations for adsorption. One of the important factors related to the chemical structure of the adsorbent is the point - zero charge $\mathrm{pH}\left(\mathrm{pH}_{\mathrm{pzc}}\right)$. At this $\mathrm{pH}$, there is no charge on the surface.
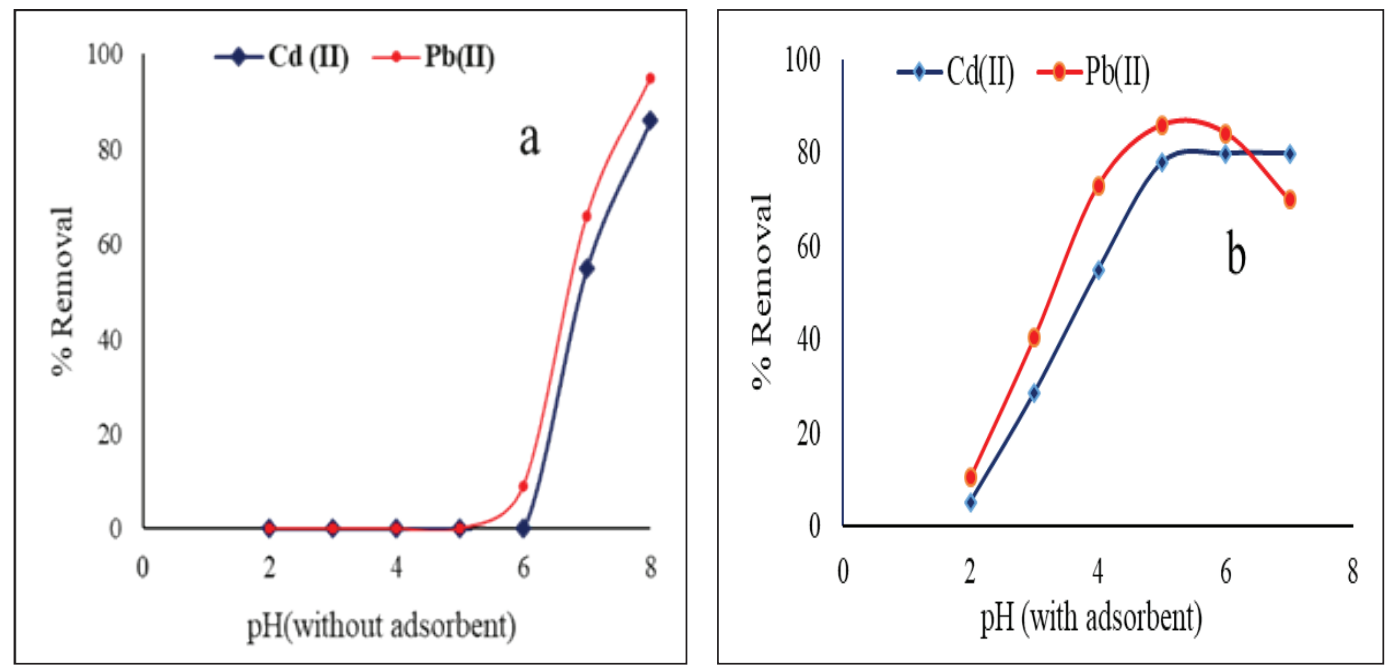

Fig.6. a) Effect of $\mathrm{pH}$ on $\mathrm{Pb}(\mathrm{II})$ and $\mathrm{Cd}(\mathrm{II})$ removal without $\mathrm{Fe}_{3} \mathrm{O}_{4}$-PPCQDs, b) with $\mathrm{Fe}_{3} \mathrm{O}_{4}$-PPCQDs adsorbent 


\subsubsection{Effect of time}

The effect of contact time on the removal of $\mathrm{Pb}$ (II) and $\mathrm{Cd}(\mathrm{II})$ by $\mathrm{Fe}_{3} \mathrm{O}_{4}$-PPCQDs was investigated to determine the optimum time taken to attain the equilibrium. The adsorption experiments were carried out by varying the contact time between 2 and 60 min, keeping all other process variables constant. Figure 7 depicts that the removal percentage was increased by increasing of the contact time. The equilibrium was achieved for $20 \mathrm{~min}$ and after this time, the further removal for $\mathrm{Pb}$ (II) and $\mathrm{Cd}$ (II) ions was not observed (constant). It was observed that, the rate of adsorption of ions was faster at initial stages, that this may be attributed to the quick uptake of ions onto the large surface area of $\mathrm{Fe}_{3} \mathrm{O}_{4}$-PPCQDs up to $20 \mathrm{~min}$ and after it the adsorption progress was slowly followed and remained constant.

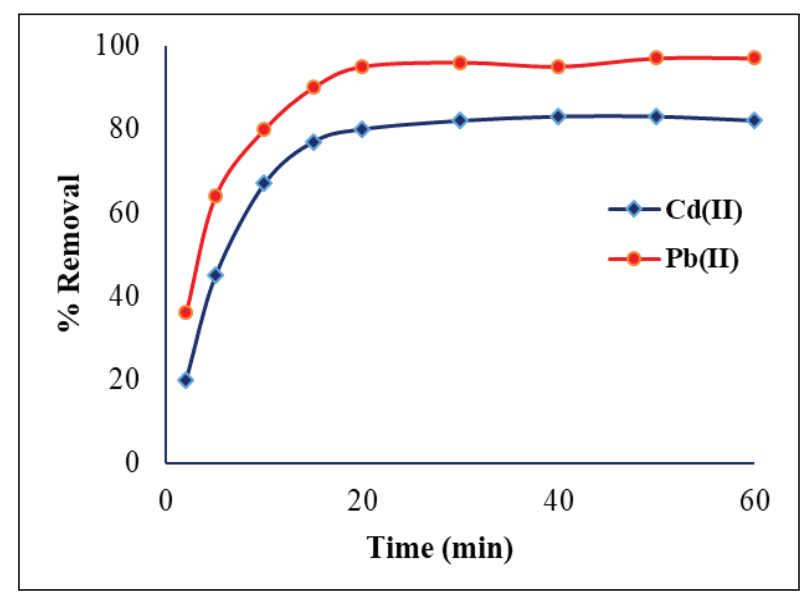

Fig. 7. Effect of contact time on $\mathrm{Pb}(\mathrm{II})$ and $\mathrm{Cd}(\mathrm{II})$ removal by $\mathrm{Fe}_{3} \mathrm{O}_{4}$-PPCQDs

\subsubsection{Effect of amount of adsorbent}

The effect of amount of $\mathrm{Fe}_{3} \mathrm{O}_{4}$-PPCQDs was investigated under optimized conditions $(\mathrm{pH}=6$ and contact time: $20 \mathrm{~min}$.). As shown in Figure 8, the adsorption increased with the $\mathrm{Fe}_{3} \mathrm{O}_{4}$-PPCQDs amount up to $0.1 \mathrm{~g}$. Also, the adsorbent surface has saturated with the extra value of $\mathrm{Pb}$ (II) and $\mathrm{Cd}(\mathrm{II})$ ions in optimized mass. At higher amount of adsorbent, the adsorption yield is almost unchanged, because the most of $\mathrm{Pb}$ (II) and $\mathrm{Cd}$ (II) ions interact with $\mathrm{Fe}_{3} \mathrm{O}_{4}$-PPCQDs surface.

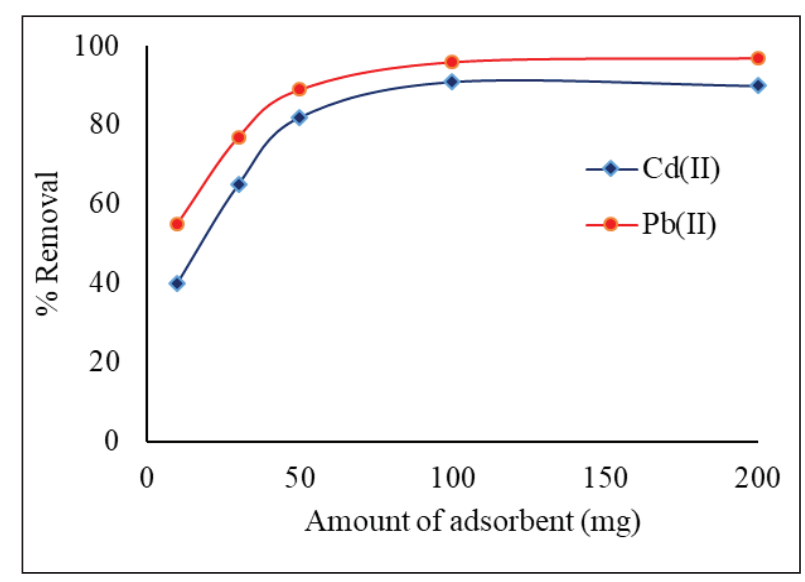

Fig. 8. The effect of adsorbent amount on $\mathrm{Pb}(\mathrm{II})$ and $\mathrm{Cd}(\mathrm{II})$ removal $\mathrm{Fe}_{3} \mathrm{O}_{4}$-PPCQDs

\subsubsection{Effect of temperature}

The effect of the temperature on adsorption of $\mathrm{Pb}$ (II) and $\mathrm{Cd}(\mathrm{II})$ ions was examined. As shown in Figure 9, the adsorption was reduced as the temperature rising $\left(5^{\circ} \mathrm{C}-45^{\circ} \mathrm{C}\right)$. The desorption of metal ions on $\mathrm{Fe}_{3} \mathrm{O}_{4}$-PPCQDs was exothermic process and by increasing temperature the removal efficiency decreased. So, the high adsorption of $\mathrm{Pb}$ (II) and $\mathrm{Cd}(\mathrm{II})$ ions on $\mathrm{Fe}_{3} \mathrm{O}_{4}$-PPCQDs adsorbent depended on the low temperature.

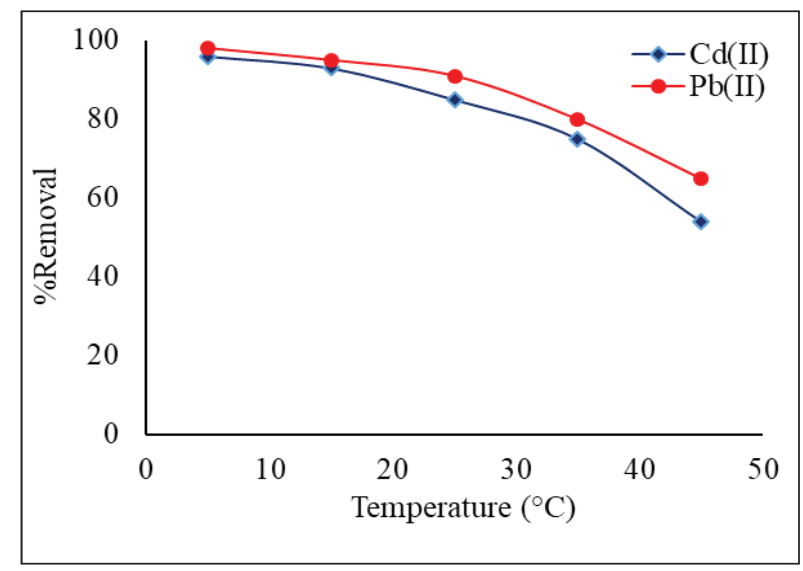

Fig. 9. The effect of temperature on $\mathrm{Pb}$ (II) and $\mathrm{Cd}(\mathrm{II})$ removal by the $\mathrm{Fe}_{3} \mathrm{O}_{4}$-PPCQDs

\subsubsection{Effect of initial concentration of Cd(II) and $\mathrm{Pb}(\mathrm{II})$}

The effect of initial concentrations of $\mathrm{Pb}$ (II) and $\mathrm{Cd}$ (II) on adsorption process based on $\mathrm{Fe}_{3} \mathrm{O}_{4}$-PPCQDs were evaluated at various concentration from 10 to 150 $\mathrm{mg} \mathrm{L} \mathrm{L}^{-1}$. In addition, the all of other parameters are 

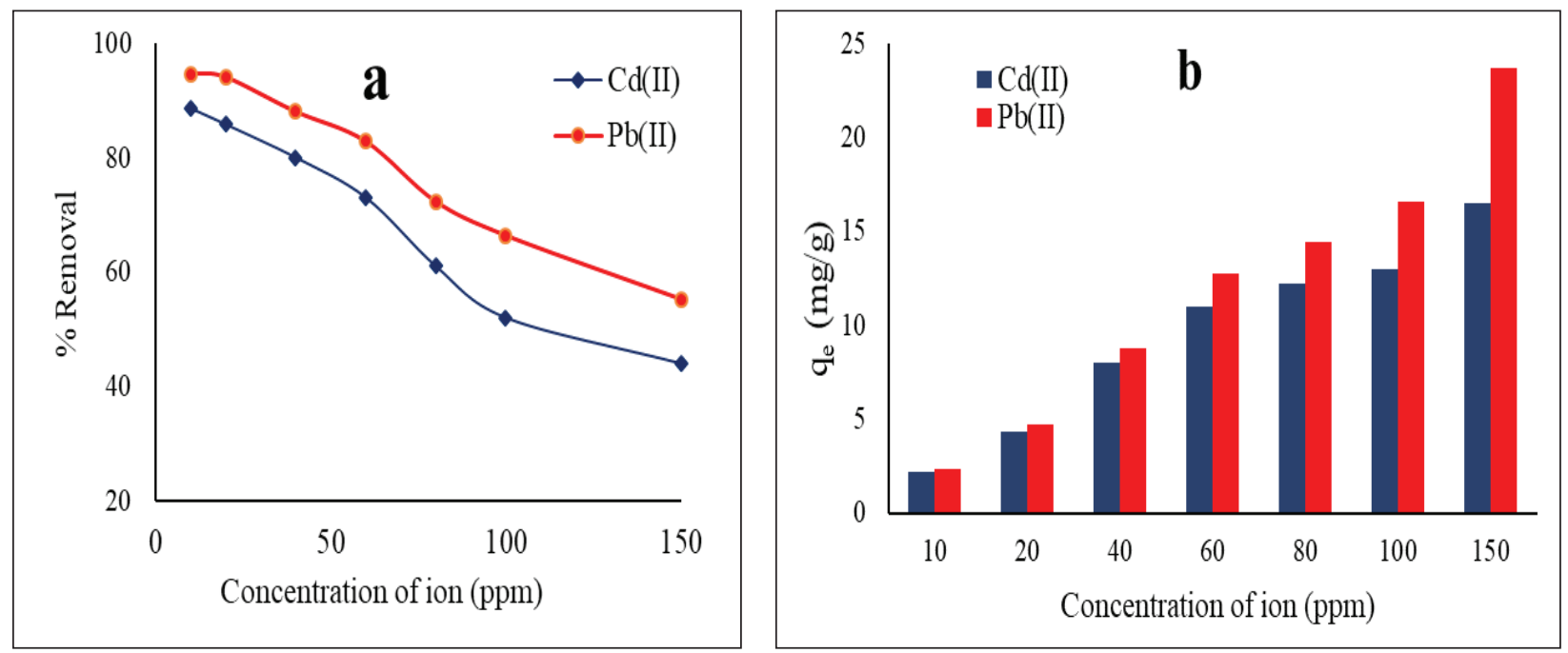

Fig. 10. a). Effect of initial metal ion concentration on $\mathrm{Pb}(\mathrm{II})$ and $\mathrm{Cd}(\mathrm{II})$ removal by $\mathrm{Fe}_{3} \mathrm{O}_{4}$-PPCQDs,

b) adsorption capacity against metal ion concentration.

constant which is shown in Figure 10a. The Figure 10a revealed that the metal removal was reduced by the $\mathrm{Fe}_{3} \mathrm{O}_{4}$-PPCQDs when the metal concentration increased from 10 to $150 \mathrm{mg} \mathrm{L}^{-1}$ in the solution. The results showed, the removal efficiencies (\%) were decreased for $\mathrm{Cd}(\mathrm{II})$ and $\mathrm{Pb}$ (II) from 88.60 to 44 and 94.61 to 55.22 , respectively. The reduce of removal efficiency (\%) by increasing the metal concentration may be due to covering /coating of the most surface sites of $\mathrm{Fe}_{3} \mathrm{O}_{4}$-PPCQDs with high concentration of $\mathrm{Pb}$ (II) and $\mathrm{Cd}$ (II) and the adsorption capacity of the adsorbent get exhausted due to non-availability of free binding sites [25]. Also, at low concentration ranges, the percentage of adsorption is high because of the availability of more active sites on the surface of adsorbent. Figure 10b showed that the adsorption capacity against ion concentrations. The increase in adsorption capacity depended on initial metal concentration which was led to increase the diffusion of $\mathrm{Pb}(\mathrm{II})$ and $\mathrm{Cd}(\mathrm{II})$ ions from the liquid phase to the surface of the solid phase. So, the driving force of the metal ions cause to lead to the collisions between metal ions and the nanoparticles surface. Therefore, the adsorption capacity was increased [23].

\subsection{Adsorption thermodynamic}

The adsorption process was analyzed by thermodynamic theory. The thermodynamic parameters viz. standard Gibb's free energy $\left(\Delta \mathrm{G}^{\circ}\right)$, standard enthalpy $\left(\Delta \mathrm{H}^{\circ}\right)$ and standard entropy $\left(\Delta \mathrm{S}^{\circ}\right)$ for the removal of $\mathrm{Pb}(\mathrm{II})$ and $\mathrm{Cd}(\mathrm{II})$ by the $\mathrm{Fe}_{3} \mathrm{O}_{4}$-PPCQDs were calculated by Equations 2-5 [26]:

$$
\begin{aligned}
& \Delta G^{\circ}=-R T \ln K \\
& \Delta H^{0}=\left[\frac{R T_{1} T_{2}}{\left(T_{2}-T_{1}\right)}\right] \ln \left(\frac{K_{2}}{K_{1}}\right) \\
& \Delta S^{0}=\left(\frac{\Delta H^{0}-\Delta G^{0}}{T}\right) \\
& K=\left(\frac{q e}{C e}\right)
\end{aligned}
$$

where $\mathrm{R}\left(8.314 \mathrm{~J} \mathrm{~mol}^{-1} \mathrm{~K}^{-1}\right)$ is the universal gas constant, $\mathrm{K}$ is the equilibrium constant at temperature $T, T$ is the absolute temperature $(K)$, $\mathrm{Ce}\left(\mathrm{mg} \mathrm{L}^{-1}\right)$ is the equilibrium concentration and qe is the amount of $\mathrm{Cd}(\mathrm{II})$ and $\mathrm{Pb}(\mathrm{II})$ adsorbed on the surface of the $\mathrm{Fe}_{3} \mathrm{O}_{4}$-PPCQDs. Figure 11 shows the relationship between $\Delta \mathrm{G}^{\circ}$ and temperature. Table 1 gives the thermodynamic parameters for adsorption of $\mathrm{Cd}(\mathrm{II})$ and $\mathrm{Pb}(\mathrm{II})$ adsorbed on the surface of the $\mathrm{Fe}_{3} \mathrm{O}_{4}$-PPCQDs adsorbent at different temperatures. As can be seen from the Table 1 the negative value of $\Delta \mathrm{G}^{\circ}$ signifies that the adsorption process is feasible and spontaneous in nature. With the increase in temperature, $\Delta \mathrm{G}^{\circ}$ shifts to more positive values indicating that the increase in temperature 
was not favorable for the adsorption process [27]. The negative value of $\Delta \mathrm{H}^{\circ}$ signifies that the adsorption process is exothermic. That was also the reason equilibrium adsorption of $\mathrm{Cd}(\mathrm{II})$ and $\mathrm{Pb}(\mathrm{II})$ decreased as the rising of solution temperature (Effect of temperature). The value of $\Delta \mathrm{S}$ were -20.31 and $-6.38 \mathrm{~J} \mathrm{~mol}^{-1} \mathrm{~K}^{-1}$ for adsorption of $\mathrm{Cd}(\mathrm{II})$ and $\mathrm{Pb}$ (II) ions, which reflected that the randomness at the interface of the $\mathrm{Fe}_{3} \mathrm{O}_{4}$-PpCQDs and solution was reduced during the adsorption process.

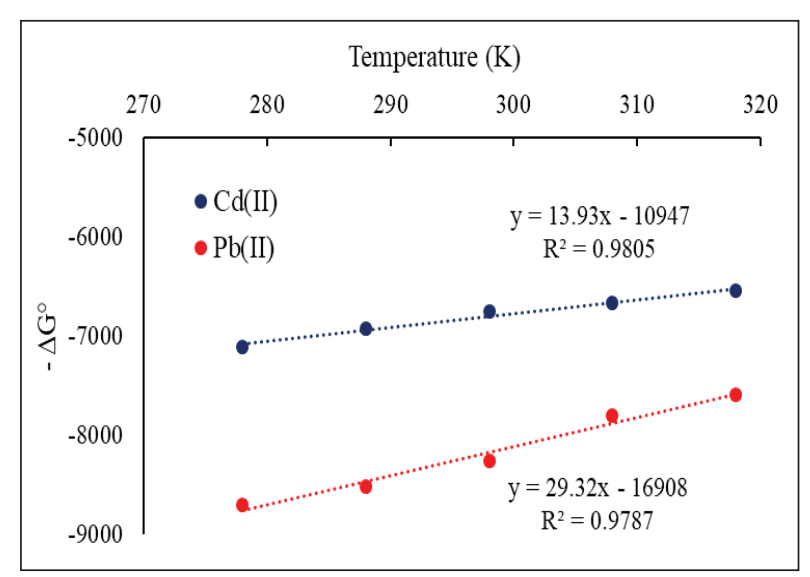

Fig.11. Relationship between $\Delta \mathrm{G}^{\circ}$ and temperature

\subsection{Adsorption isotherms}

The most popular isotherms are Langmuir and Freundlich [28] models. The Langmuir model describes monolayer adsorption, however Freundlich model show heterogeneous surface. The linear form of Langmuir model is given by following Equation 6:

$$
\frac{C_{\mathrm{e}}}{q_{\mathrm{e}}}=\frac{1}{\left(K_{\mathrm{L}} q_{\mathrm{m}}\right)}+\frac{C_{\mathrm{e}}}{q_{\mathrm{m}}}
$$

where $\mathrm{C}_{\mathrm{e}}\left(\mathrm{mg} \mathrm{L}^{-1}\right)$ is the equilibrium concentration of the solution, $\mathrm{q}_{\mathrm{e}}\left(\mathrm{mg} \mathrm{g}^{-1}\right)$ is the amount of metal adsorbed per specific amount of adsorbent, $\mathrm{q}_{\mathrm{m}}(\mathrm{mg}$ $\left.\mathrm{g}^{-1}\right)$ is the maximum amount of metal ions required to form monolayer, $\mathrm{K}\left(\mathrm{L} \mathrm{mg}^{-1}\right)$ is the adsorption equilibrium constant (Fig. 12). Freundlich adsorption model demonstrate that adsorbents have a heterogeneous surface having site with different adsorption potential. It moreover expects that stronger binding sites are occupied first and the binding strength decreases with the increasing degree of occupation. The Freundlich adsorption model in its linear form is given in Equation 7:

$$
\log _{10} q_{e}=\log _{10}\left(K_{f}\right)+\left(\frac{1}{n}\right) \log _{10}\left(C_{e}\right) \text { (Eq. 7) }
$$

where $\mathrm{K}_{\mathrm{f}}\left(\mathrm{mg} \mathrm{g}^{-1}\right)$ is the Freundlich constant indicating adsorption capacity, $\mathrm{n}\left(\mathrm{L} \mathrm{mg}^{-1}\right)$ is the adsorption intensity that is the measure of the change in affinity of the adsorbate with the change in adsorption density. The Freundlich constants $\mathrm{K}_{\mathrm{f}}$ and $\mathrm{n}$ were calculated from the slope and intercept of the plot of Ce versus $\log 10$ qe (Fig. 13) that shown in Table 2. The values of Langmuir $\mathrm{R}^{2}$ for $\mathrm{Cd}$ (II) and $\mathrm{Pb}$ (II) by the $\mathrm{Fe}_{3} \mathrm{O}_{4}$-PPCQDs were higher than Freundlich model thus, indicating that Langmuir model fitted the data in good congruence, thereby indicating monolayer adsorption.

\begin{tabular}{|c|c|c|c|c|c|}
\hline \multicolumn{6}{|c|}{$\mathrm{Fe}_{3} \mathrm{O}_{4}$-PPCQDs at different temperatures } \\
\hline Ion & $\mathbf{T}(\mathbf{K})$ & $\Delta \mathrm{G}\left(\mathrm{J} \mathrm{mol}^{-1}\right)$ & $\Delta \mathbf{H}\left(\mathrm{J} \mathrm{mol}^{-1}\right)$ & $\Delta \mathrm{S}\left(\mathrm{J} \mathrm{mol}^{-1}\right)$ & $\mathbf{R}^{2}$ \\
\hline \multirow{5}{*}{$\mathrm{Pb}(\mathrm{II})$} & 278 & -8700 & \multirow{5}{*}{-16908} & \multirow{5}{*}{-29.32} & \multirow{5}{*}{0.978} \\
\hline & 288 & -8510 & & & \\
\hline & 298 & -8256 & & & \\
\hline & 308 & -7800 & & & \\
\hline & 318 & -7589 & & & \\
\hline \multirow{5}{*}{ Cd (II) } & 278 & -7105 & \multirow{5}{*}{-10947} & \multirow{5}{*}{-13.93} & \multirow{5}{*}{0.980} \\
\hline & 288 & -6923 & & & \\
\hline & 298 & -6748 & & & \\
\hline & 308 & -6664 & & & \\
\hline & 318 & -6538 & & & \\
\hline
\end{tabular}

Table 1. Thermodynamic parameters for adsorption of $\mathrm{Pb}(\mathrm{II})$ and $\mathrm{Cd}(\mathrm{II})$ by 


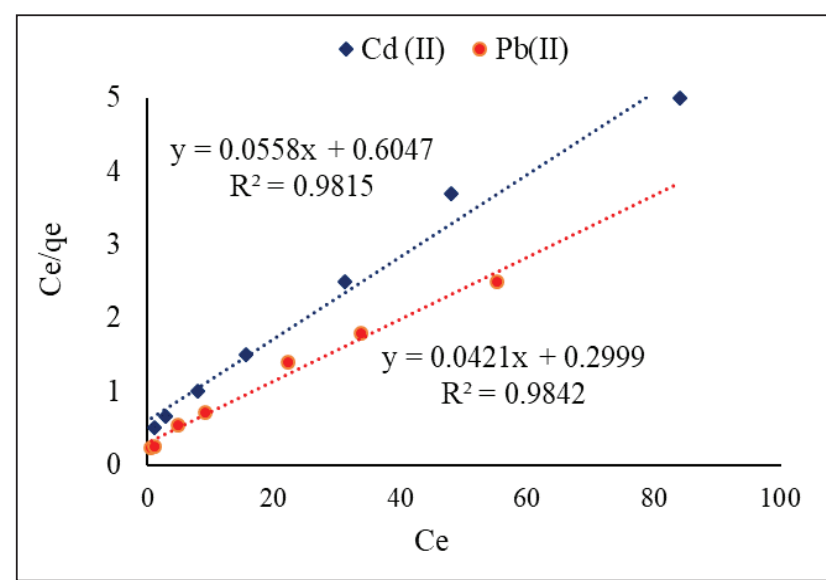

Fig. 12. Linear Langmuir isotherm for $\mathrm{Pb}(\mathrm{II})$ and $\mathrm{Cd}(\mathrm{II})$ removal by the $\mathrm{Fe}_{3} \mathrm{O}_{4}$-PPCQDs.

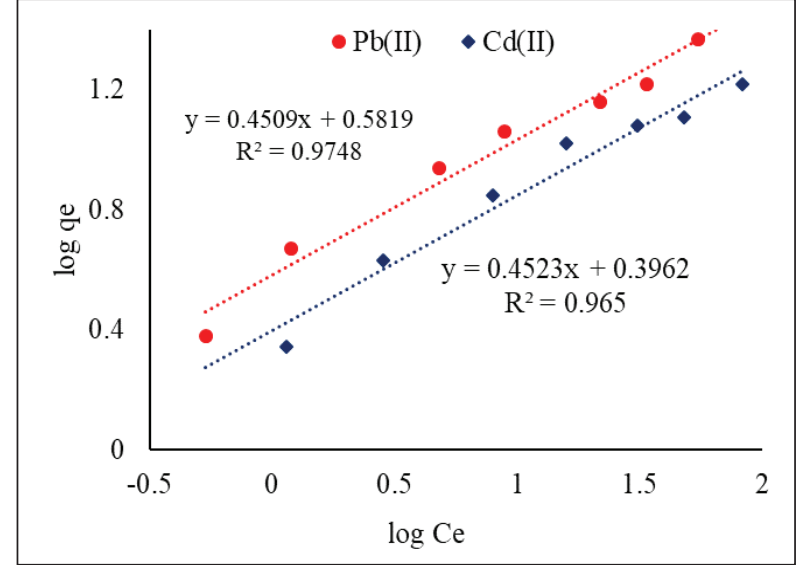

Fig. 13. Linear Freundlich isotherm for $\mathrm{Pb}(\mathrm{II})$ and $\mathrm{Cd}(\mathrm{II})$ removal by the $\mathrm{Fe}_{3} \mathrm{O}_{4}$-PPCQDs.

Table 2. Langmuir and Freundlich isotherm parameters for the removal of $\mathrm{Pb}(\mathrm{II})$ and $\mathrm{Cd}(\mathrm{II})$ by the $\mathrm{Fe}_{3} \mathrm{O}_{4}-\mathrm{PPCQDs}$

\begin{tabular}{lll}
\hline Parameters & $\mathbf{P b}(\mathrm{II})$ & $\mathbf{C d}(\mathrm{II})$ \\
\hline Langmuir parameters & & \\
$\mathrm{q}_{\mathrm{m}}\left(\mathrm{mg} \mathrm{g}^{-1}\right)$ & 23.75 & 17.92 \\
$\mathrm{~b}\left(\mathrm{~L} \mathrm{mg}^{-1}\right)$ & 0.120 & 0.092 \\
$\mathrm{R}^{2}$ & 0.9842 & 0.9815 \\
\hline Freundlich Parameters & & \\
$\mathrm{K}_{\mathrm{f}}\left(\mathrm{mg} \mathrm{g}^{-1}\right)$ & 3.82 & 2.5 \\
$\mathrm{n}\left(\mathrm{L} \mathrm{mg}^{-1}\right)$ & 2.22 & 2.21 \\
$\mathrm{R}^{2}$ & 0.9748 & 0.965 \\
\hline
\end{tabular}

\subsection{Comparison of adsorption capacity with other adsorbents}

The maximum adsorption capacity of $\mathrm{Fe}_{3} \mathrm{O}_{4}$-PPCQDs nanocomposite for the removal of $\mathrm{Pb}$ (II) and $\mathrm{Cd}(\mathrm{II})$ was compared with other adsorbents reported in the literature and the values are given in Table 3. It is clear from Table 3, that the adsorption capacity of $\mathrm{Fe}_{3} \mathrm{O}_{4}^{-}$ PPCQDs. is comparable with other nanomaterials suggesting that, it is effective in removing $\mathrm{Pb}(\mathrm{II})$ and $\mathrm{Cd}(\mathrm{II})$ from aqueous solutions [29-33].

Table 3. Comparison of adsorption capacity of the $\mathrm{Fe}_{3} \mathrm{O}_{4}$-PPCQDs with other adsorbents.

\begin{tabular}{|c|c|c|c|c|c|}
\hline \multirow{2}{*}{ Adsorbents } & \multicolumn{2}{|c|}{ Adsorption capacity (mg g $\left.{ }^{-1}\right)$} & \multirow{2}{*}{ pH } & \multirow{2}{*}{$\begin{array}{l}\text { Adsorbent } \\
\text { mass (mg). }\end{array}$} & \multirow{2}{*}{ Ref. } \\
\hline & Cd (II) & $\mathrm{Pb}$ (II) & & & \\
\hline $\mathrm{CFe}_{3} \mathrm{O}_{4}$ & 4.106 & 3.795 & 3 & 50 & 29 \\
\hline PMNPs & 29.60 & 3.103 & 1 to 8 & 50 & 30 \\
\hline Kaniar $\mathrm{Fe}_{3} \mathrm{O}_{4}$ & 2.20 & 1.35 & 5 & 200 & 31 \\
\hline MCANF & ----- & 44 & 6 & 100 & 32 \\
\hline Sawdust (Fe3O4/SC) & 63 & ----- & 6.5 & 400 & 33 \\
\hline This study & 17.92 & 23.75 & 6 & 100 & ---- \\
\hline
\end{tabular}

$\mathrm{CFe}_{3} \mathrm{O}_{4}$ : Chitosan/iron oxide nanocomposite

PMNPs: Polymer-modified magnetic nanoparticles

Kaniar $\mathrm{Fe}_{3} \mathrm{O}_{4}$ : Magnetic Bauhinia purpurea (Kaniar) powders

MCANF: $\mathrm{Fe}_{3} \mathrm{O}_{4}$ nanoparticles onto cellulose acetate nanofibers nanocomposite 


\section{Conclusions}

In this article, the adsorption potential of the $\mathrm{Fe}_{3} \mathrm{O}_{4}-$ PPCQDs nanocomposite was investigated for the removal of $\mathrm{Pb}(\mathrm{II})$ and $\mathrm{Cd}(\mathrm{II})$ ions. TEM analysis revealed that the synthesized nanoparticles have an average particle size of $10-25 \mathrm{~nm}$ for the $\mathrm{Fe}_{3} \mathrm{O}_{4}$ PPCQDs. The XRD analysis of $\mathrm{Fe}_{3} \mathrm{O}_{4}$-PPCQDs confirmed the presence of magnetite phase exhibiting average crystal size similar to that indicated by the TEM analysis. Batch adsorption experiments were led to study the effect of various parameters like agitation time, adsorbent dosage, initial concentration of the $\mathrm{Pb}$ (II) and $\mathrm{Cd}(\mathrm{II})$, temperature, and $\mathrm{pH}$. The conditions for the highest removal efficiency of synthesized nanocomposite for the removal of $\mathrm{Pb}$ (II) and $\mathrm{Cd}$ (II) were achieved $(\mathrm{pH}=6.0$, temperature $=25$ $\pm 1{ }^{\circ} \mathrm{C}$, initial metal ion concentration $=50 \mathrm{mg} \mathrm{L}^{-1}$ contact time $=20 \mathrm{~min}$ ). Based on procedure, the maximum Langmuir adsorption capacity was obtained $17.92 \mathrm{mg} \mathrm{g}^{-1}$ for $\mathrm{Cd}(\mathrm{II})$ and $23.75 \mathrm{mg}$ $\mathrm{g}^{-1}$ for $\mathrm{Pb}(\mathrm{II})$ at $\mathrm{pH}$ 6. In addition, the working ranges of cadmium and lead adsorption based on $\mathrm{Fe}_{3} \mathrm{O}_{4}$-PPCQDs nanocomposite in $50 \mathrm{~mL}$ of water samples were obtained 4-36 $\mu \mathrm{g} \mathrm{L}^{-1}$ and 50-400 $\mu \mathrm{g}$ $\mathrm{L}^{-1}$, respectively by the MSPE procedure $(\mathrm{PF}=50$, RSD $\%<2.4)$. Therefore, the ultra- trace analysis of $\mathrm{Pb}$ (II) and $\mathrm{Cd}$ (II) ions was done by $\mathrm{Fe}_{3} \mathrm{O}_{4}$ PPCQDs nanocomposite at $\mathrm{pH}=6$.

\section{Acknowledgments}

The authors would like to thank from Department of Chemistry, Kerman Branch, Islamic Azad University, Kerman, Iran.

\section{References}

[1] A. T. Jan, M. Azam, K. Siddiqui, A.A.I. Choi, Q.M.R. Haq, Heavy metals and human health: mechanistic insight into toxicity and counter defense system of antioxidants. Int. J. Mol. Sci., 16 (2015) 29592-29630.

[2] R. Singh, N. Gautam, A. Mishra, R. Gupta, Heavy metals and living systems: an overview. Indian J. Pharmacol., 43 (2011) 246-253.
[3] W. Shotyk, G.L. Roux, A. Sigel, H. Sigel, R.K.O. Sigel, Metal ions in biological systems, Taylor and Francis, Boca Raton, Chapter 10, 2005.

[4] M.A.A. Zaini, R. Okayama, M. Machida, Adsorption of aqueous metal ions on cattlemanure compost based activated carbons, J. Hazard. Mater., 170 (2009) 1119-1124.

[5] A. Vázquez-Guerrero, R. Cortés-Martínez, R. A. Cuevas-Villanueva, E. M. RiveraMuñoz, R. Huirache-Acuña, Cd(II) and $\mathrm{Pb}$ (II) adsorption using a composite obtained from Moringa oleifera Lam, cellulose nanofibrils impregnated with iron nanoparticles, Water, 13 (2021) 89.

[6] W. Zhang, X. Shi, Y. Zhang, W. Gu, B. $\mathrm{Li}$, Synthesis of water-soluble magnetic graphene nanocomposites for recyclable removal of heavy metal ions, J. Mater. Chem. A, 1 (2013) 1745-1753.

[7] H. Isawi, Using zeolite/polyvinyl alcohol/ sodium alginate nanocomposite beads for removal of some heavy metals from wastewater, Arab. J. Chem., 13 (2020) 5691-5716.

[8] R. Ahmad, A. Mirza, Facile one pot green synthesis of chitosan-iron oxide $\left(\mathrm{CS}-\mathrm{Fe}_{2} \mathrm{O}_{3}\right)$ nanocomposite: removal of $\mathrm{Pb}(\mathrm{II})$ and $\mathrm{Cd}(\mathrm{II})$ from synthetic and industrial wastewater, J. Clean. Prod., 186 (2018) 342-352.

[9] H. C. Tao, H. R. Zhang, J. B. Li, W. Y. Ding, Biomass based activated carbon obtained from sludge and sugarcane bagasse for removing lead ion from wastewater, Bioresour. Technol., 192 (2015) 611-617.

[10] M. F. Gao, Q. L. Ma, Q.W. Lin, J. L. Chang, H. Z. Ma, A novel approach to extract $\mathrm{SiO}_{2}$ from fly ash and its considerable adsorption properties, Mater. Design., 116 (2017) 666 675.

[11] Y. K. Tang, L. Chen, X. R. Wei, Q. Y. Yao, T. Li, Removal of lead ions from aqueous solution by the dried aquatic plant, Lemna perpusilla Torr, J. Hazard. Mater., 244 (2013) 603-612. 
[12] J. G. Wang, J. Wei, J. Li, Rice straw modified by click reaction for selective extraction of noble metal ions, Bioresour. Technol., 177 (2015) 182-187.

[13] T. M. Abdel-Fattah, M. E. Mahmoud, S. B. Ahmed. Biochar from woody biomass for removing metal contaminants and carbon sequestration, J. Ind. Eng. Chem., 22 (2015) 103-109.

[14] S. Haider, F.A.A. Ali, A. Haider, W. A. AlMasry, Y. Al-Zeghayer, Novel route for amine grafting to chitosan electrospun nanofibers membrane for the removal of copper and lead ions from aqueous medium, Carbohydr. Polym., 199 (2018) 406-414.

[15] Q. Feng, D. Wu, Y. Zhao, A. Wei, Q. Wei, H. Fong, Electrospun AOPAN/RC blend nanofiber membrane for efficient removal of heavy metal ions from water, J. Hazard. Mater., 344 (2018) 819-828.

[16] Q. Lv, X. Hu, X. Zhang, L. Huang, Z. Liu, G. Sun, Highly efficient removal of trace metal ions by using poly (acrylic acid) hydrogel adsorbent, Mater. Design., 181 (2019) 107934.

[17] F. Arshad, M. Selvaraj, J. Zain, F. Banat, M. Abu Haija, Polyethylenimine modified graphene oxide hydrogel composite as an efficient adsorbent for heavy metal ions, Sep. Purif. Technol., 209 (2019) 870-880.

[18] R. Song, M. Murphy, C. Li, K. Ting, C. Soo, Z. Zheng, Current development of biodegradable polymeric materials for biomedical applications, Drug Des. Devel. Ther., 24 (2018) 3117-3145.

[19] H. Baweja, K. Jeet, Economical and green synthesis of graphene and carbon quantum dots from agricultural waste, Mater. Res. Express, 6 (2019) 0850g8.

[20] M. M. Rhaman, M. R. Karim, M. K. Mohammad Ziaul, Y. Ahmed, Removal of chromium (VI) from effluent by a magnetic bioadsorbent based on Jute Stick powder and its adsorption isotherm, kinetics and regeneration study, Water Air Soil Pollut.,
231 (2020) 1-18.

[21] P.N. Dave, L.V. Chopda, Application of iron oxide nanomaterials for the removal of heavy metals, J. Nanotechnol., 4 (2014) 1-14

[22] M.O. Ojemaye, O.O. Okoh, A.I. Okoh, Surface modified magnetic nanoparticles as efficient adsorbents for heavy metal removal from wastewater, progress and prospects, Mater. Express, 7 (2017) 439-456.

[23] B. R. Seeram, M. Lee, D. Heber, Rabid large scale purification of ellagitunnins from pomegranate husk, Sep. Puri. Technol., 41 (2005) 49-55.

[24] H. Wang, X. Xu, Z. Ren, B. Gao, Removal of phosphate and chromium(VI) from liquids by an aminecrosslinked nano- $\mathrm{Fe}_{3} \mathrm{O}_{4}$ biosorbent derived from corn straw, RSC Adv., 6 (2016) 47237-47248.

[25] M. Jain, M Yadav, T. Kohout, M. Lahtinen, V.K. Garg, Development of iron oxide/ activated carbon nanoparticle composite for the removal of $\mathrm{Cr}(\mathrm{VI}), \mathrm{Cu}(\mathrm{II})$ and $\mathrm{Cd}(\mathrm{II})$ ions from aqueous solution, Water Resour. Ind., 20 (2018) 54-74

[26] M.I. Panayotova, Kinetics and thermodynamics of copper ions removal from wastewater by use of zeolite, Waste Manag., 21 (2001) 671-676.

[27] L. Xu, X. Zheng, H. Cui, Z. Zhu, J. Liang, J. Zhou, Equilibrium, kinetic, and thermodynamic studies on the adsorption of cadmium from aqueous solution by modified biomass ash, Bioinorg. Chem. Appl., 2017 (2017) 1-9. https://doi. org $/ 10.1155 / 2017 / 3695604$

[28] H. Zare, H. Heydarzadeh, M. Rahimnejad, A. Tardast, M. Seyfi, S.M. Peyghambarzade, Dried activated sludge as an appropriate biosorbent for removal of copper (II) ions, Arab. J. Chem., 8 (2015) 858-864.

[29] M. Keshvardoostchokami, L. Babaei, A. A. Zamani, A. H. Parizanganeh, F. Piri, Synthesized chitosan/iron oxide nanocomposite and shrimp shell in removal 
of nickel, cadmium and lead from aqueous solution, Global J. Environ. Sci. Manag., 3 (2017) 267-278.

[30] F. Ge, M. Li, H. Ye, B. Zhao, Effective removal of heavy metal ions $\mathrm{Cd}^{2+}, \mathrm{Zn}^{2+}, \mathrm{Pb} 2+, \mathrm{Cu}^{2+}$ from aqueous solution by polymer-modified magnetic nanoparticles, J. Hazard. Mater., 211 (2012) 366-372.

[31] R. Sharma, A. Sarswat, C.U. Pittman, D. Mohan, Cadmium and lead remediation using magnetic and non-magnetic sustainable biosorbents derived from bauhinia Purpurea Pods, RSC Adv., 7 (2017) 8606-8624.

[32] T. I. Shalaby, M.F. El-Kady, A.E.H.M. Zaki, S. M. El-Kholy. Preparation and application of magnetite nanoparticles immobilized on cellulose acetate nanofibers for lead removal from polluted water, Water Supply, 17 (2017) 176-187.

[33] N. Kataria, V. K. Garg, Green synthesis of $\mathrm{Fe}_{3} \mathrm{O}_{4}$ nanoparticles loaded sawdust carbon for cadmium (II) removal from water: regeneration and mechanism, Chemosphere, 208 (2018) 818-828. 